Check for updates

Cite this: RSC Adv., 2017, 7, 23021

Received 24th February 2017 Accepted 18th April 2017

DOI: $10.1039 / c 7 r a 02312$

rsc.li/rsc-advances

\section{Involvement of ROS in nanosilver-caused suppression of aflatoxin production from Aspergillus flavus $\dagger$}

\begin{abstract}
Jing Zhao, ${ }^{\text {ab }}$ Ling Wang, ${ }^{\text {ab }}$ Dan $\mathrm{Xu}^{* \mathrm{~cd}}$ and Zhisong Lu (D) *ab
Silver nanoparticles (AgNPs) have been extensively studied as antimicrobial materials, but their capability of suppressing aflatoxin production has not been investigated. In this work, AgNPs with an average size of $4.5 \mathrm{~nm}$ were synthesized to inhibit the growth of Aspergillus flavus (A. flavus). Based on the anti-fungal assay, the concentration of $5 \mu \mathrm{g} \mathrm{mL}{ }^{-1}$ was chosen to study the direct inhibiting effects of AgNPs on aflatoxin production. Results show that AgNP treatment could significantly decrease secretion of aflatoxin $\mathrm{B}_{1}$ from $A$. flavus. Real-time measurements of $\mathrm{O}_{2}{ }^{-}$with an electrochemical sensor reveal that the AgNPs could trigger the release of $\mathrm{O}_{2}{ }^{-}$from fungal mycelia. A mechanism involving $\mathrm{O}_{2}{ }^{-}$release is proposed to explain AgNP-caused depression of aflatoxin production from A. flavus. This is the first attempt to study AgNP-induced inhibition on aflatoxin generation and its possible mechanisms.
\end{abstract}

\section{Introduction}

Aflatoxins, the secondary metabolites of Aspergillus flavus (A. flavus), Aspergillus parasiticus (A. parasiticus) and Aspergillus nonius (A. nonius), ${ }^{1}$ are a group of highly toxic substances that cause acute or chronic human liver diseases. ${ }^{2,3}$ Among them, aflatoxin $\mathrm{B}_{1}\left(\mathrm{AFB}_{1}\right)$ is recognized as the most toxic natural substance. At a very low level, $\mathrm{AFB}_{1}$ leads to significantly negative impacts on human and animal health. ${ }^{4}$ Since agricultural products such as peanut, corn, rice and wheat are easily contaminated by fungi, ${ }^{5}$ great efforts have been devoted to the development of efficient ways to suppress $\mathrm{AFB}_{1}$ production.

Essential oils extracted from plants have been applied to inhibit fungal growth and mycotoxin production in recent years. $^{6}$ Essential oils including aldehydes (cinnamaldehyde, citral, citronellal and neral), phenols (thymol, eugenol, phenol and thymol), alcohols (linalool and citronellol), as well as ketones (carvone and menthone) have been regarded as

\footnotetext{
${ }^{a}$ Chongqing Key Laboratory for Advanced Materials \& Technologies of Clean Energies, Southwest University, No. 1 Tiansheng Road, Chongqing 400715, P. R. China. E-mail: zslu@swu.edu.cn

${ }^{b}$ Chongqing Engineering Research Center for Micro-Nano Biomedical Materials and Devices, Institute for Clean Energy \& Advanced Materials, Faculty of Materials and Energy, Southwest University, No. 1 Tiansheng Road, Chongqing 400715, P. R. China ${ }^{c}$ Department of Gastroenterology, The Central Hospital of Wuhan, Tongji Medical College, Huazhong University of Science and Technology, Shengli Street Jiang'an District No. 26, Wuhan 430014, P. R. China.E-mail: drxu0624@gmail.com

${ }^{d}$ Key Laboratory for Molecular Diagnosis of Hubei Province, The Central Hospital of Wuhan, Tongji Medical College, Huazhong University of Science and Technology, Shengli Street Jiang'an District No. 26, Wuhan 430014, P. R. China

$\dagger$ Electronic supplementary information (ESI) available. See DOI: $10.1039 / \mathrm{c} 7 \mathrm{ra} 02312 \mathrm{j}$
}

effective antifungal reagents. ${ }^{7-11}$ As advances of nanotechnology, nanomaterials have also been employed to inhibit fungal growth. ${ }^{\mathbf{1 2 - 1 6}}$ Single-walled carbon nanotubes (SWCNTs), multi-walled carbon nanotubes (MWCNTs), graphene oxide nanosheets and reduce graphene oxide nanosheets have been proven to possess antifungal activities against Fusarium graminearum and Fusarium poae..$^{\mathbf{1 2 - 1 6}}$

As a nanomaterial with a broad bactericidal spectrum and long-lasting antimicrobial effects, nanosilver has also been applied to inhibit microbial growth. ${ }^{17-22}$ Nanosilver has been practically used as fresh-keeping packaging materials, food additives and food coating materials to control the growth of microbes in food and vegetables. ${ }^{23,24}$ A significant inhibitory effect on the growth of Candida albicans and Aspergillus could be achieved by using nanosilver as antifungal materials. The antifungal activity of silver nanoparticles (AgNPs) against Alternaria solani and Fusarium oxysporum has also been verified. ${ }^{25}$ Although nanosilver is a very promising material to restrain the growth of fungi including Aspergillus species, its capability of suppressing aflatoxin production in Aspergillus has not been systematically investigated so far.

Reactive oxygen species (ROS), which are closely related to a great deal of biological events such as aging, cancer development, and neurodegenerative diseases, ${ }^{26-32}$ may also participate in the generation of aflatoxins in A. flavus. ${ }^{33}$ Enhancement of oxidative stress leads to a higher level of aflatoxins production from toxigenic strains. ${ }^{34}$ Moreover, the application of antioxidants could reduce biosynthesis of aflatoxins from Aspergillus species. ${ }^{35,36}$ In our recent work, we demonstrated that the secretion of ROS upon citral stimulation might be the mechanism for citral-induced reduction of $\mathrm{AFB}_{1}$ production from $A$. flavus. ${ }^{30}$ 
In the present study, AgNPs synthesized via a wet-chemical approach were characterized with TEM and UV-vis spectrometry. The anti-fungal activity of the as-prepared AgNPs was evaluated by measuring their growth inhibition effects on A. flavus. A low concentration of AgNPs, which cannot cause a significant growth inhibition effect, was chosen to investigate direct effects of AgNPs on aflatoxin production. Release of $\mathrm{O}_{2}{ }^{-}$from $A$. flavus upon the stimulation of AgNPs was real-time monitored using a MWCNTs- $\mathrm{Mn}_{3} \mathrm{O}_{4}$ nanorods-based biosensor to reveal the possible mechanism for AgNPs-induced aflatoxin suppression.

\section{Experimental}

\section{Reagents and materials}

A. flavus GZ-6 was a gift from Institute of Agro-Products Processing Science and Technology, Chinese Academy of Agricultural Sciences, P. R. China. The MWCNTs, sucrose and yeast extract were purchased from Aladdin (Shanghai, China). Soybean peptone was bought from Qingdao Hope BioTechnology Co. Ltd. (Qingdao, China). Nafion perfluorinated resin (Sigma-Aldrich, China) was dissolved in absolute ethanol to form a 5\% Nafion solution. All other chemicals were of analytical grade and directly used in the present study without further purifications.

\section{Preparation of standard $\mathrm{O}_{2}^{-}$solutions}

The standard $\mathrm{O}_{2}{ }^{-}$solutions were prepared by adding $\mathrm{KO}_{2}$ powder into nitrogen gas-saturated phosphate-buffered saline (PBS). The concentration of $\mathrm{O}_{2}^{-}$solution was determined spectrophotometrically using the ferrocytochrome $\mathrm{C}$ reduction assay, in which the absorbance change at $550 \mathrm{~nm}$ was recorded to calculate the amount of $\mathrm{O}_{2}{ }^{-}$with the extinction coefficient of $21.1 \mathrm{mM}^{-1} \mathrm{~cm}^{-1}$.

\section{Synthesis of AgNPs and $\mathrm{Mn}_{3} \mathrm{O}_{4}$ nanorods}

AgNPs were synthesized according to Shirtcliffe's route with minor modifications. ${ }^{36}$ Briefly, $1 \mathrm{~mL} \mathrm{AgNO}_{3}$ solution $(0.01 \mathrm{M})$ and $1 \mathrm{~mL}$ sodium citrate dihydrate solution $(0.01 \mathrm{M})$ were mixed with $20 \mathrm{~mL}$ deionized water at $70{ }^{\circ} \mathrm{C}$. Then, a $\mathrm{NaBH}_{4}-\mathrm{NaOH}$ solution, which was freshly prepared by dissolving $0.0189 \mathrm{~g}$ $\mathrm{NaBH}_{4}$ in $50 \mathrm{~mL}$ of $0.1 \mathrm{M} \mathrm{NaOH}$ solution, was added into the above mixture under stirring. The color of the solution changed to bright yellow instantly, showing the successful synthesis of AgNPs.

$\mathrm{Mn}_{3} \mathrm{O}_{4}$ nanorods were fabricated with the following way: firstly, $0.2 \mathrm{~g}$ poly(vinylpyrrolidone) and $0.1 \mathrm{~g}$ stearic acid were mixed in $15 \mathrm{~mL}$ ethanol under stirring for $15 \mathrm{~min}$. Then, $45 \mu \mathrm{L}$ $\mathrm{Mn}\left(\mathrm{NO}_{3}\right)_{2}(50 \mathrm{wt} \%)$ and $400 \mu \mathrm{L} \mathrm{H}_{2} \mathrm{O}_{2}(30 \%)$ were added into the mixture successively, stirring for another $15 \mathrm{~min}$. After heating at $160{ }^{\circ} \mathrm{C}$ for $8 \mathrm{~h}$, the $\mathrm{Mn}_{3} \mathrm{O}_{4}$ nanorods were produced and harvested by centrifugation (12 $\left.000 \mathrm{rpm} \mathrm{min}^{-1}, 10 \mathrm{~min}\right)$.

\section{Fabrication of $\mathrm{Mn}_{3} \mathrm{O}_{4}$ nanorods-MWCNTs-modified electrodes}

Glassy carbon electrodes (GCEs) were polished with $0.05 \mu \mathrm{m}$ alumina slurry on a piece of chamois leather to achieve a smooth surface. $5 \mu \mathrm{L}$ well-dispersed MWCNTs suspension ( $1 \mathrm{mg} \mathrm{mL}^{-1}$ ) and $\mathrm{Mn}_{3} \mathrm{O}_{4}$ nanorods $\left(7.5 \mathrm{mg} \mathrm{mL}^{-1}\right.$ ) were dropped onto the GCE surface successively to produce the modified electrode. A 5\% Nafion solution was coated on the modified GCEs, storing at $4{ }^{\circ} \mathrm{C}$ for the electrochemical tests.

\section{Culture of A. flavus and AgNPs treatment}

A. flavus was inoculated in a culture medium $\left(450 \mathrm{~g} \mathrm{~L}^{-1}\right.$ sucrose, $60 \mathrm{~g} \mathrm{~L}^{-1}$ yeast extract and $30 \mathrm{~g} \mathrm{~L}^{-1}$ soybean peptone in deionized water) and incubated at $30^{\circ} \mathrm{C}$ under constant shaking (200 rpm) for 3 days. The A. flavus mycelia were harvested via filtration and washed with PBS for 3 times. The mycelia were re-suspended in a PBS solution and treated with $5 \mu \mathrm{g} \mathrm{mL}{ }^{-1}$ AgNPs at $30{ }^{\circ} \mathrm{C}$ for 60 seconds. After washing for 3 times, the PBS- and AgNPs-treated mycelia were inoculated in fresh media, culturing at $30{ }^{\circ} \mathrm{C}$ under constant shaking. The media sampled at 0,72 and $96 \mathrm{~h}$ were stored at $4{ }^{\circ} \mathrm{C}$ for the determination of the AFB1 concentrations.

The collected media were filtered through a Waterman filter. The $\mathrm{AFB}_{1}$ was extracted from the filtrates with chloroform, followed by the dehydration with anhydrous sodium sulfate and the evaporation at $50{ }^{\circ} \mathrm{C}$ under vacuum. The amount of $\mathrm{AFB}_{1}$ was determined with a high-performance liquid chromatography (HPLC) containing an ultraviolet/visible spectrum Waters 2475 detection system (Waters Corporation, Milford, MA, USA).

\section{Materials characterization and electrochemical measurements}

Morphologies of the nanomaterials were characterized with SEM (JSM-7600, JEOL, Tokyo, Japan) and TEM (JEM-2100, JEOL, Tokyo, Japan). XRD spectra were examined using a $\mathrm{Cu} \mathrm{K} \alpha$-ray with tube conditions of $40 \mathrm{kV}$ and $30 \mathrm{~mA}$ ranging from $10^{\circ}$ to $80^{\circ}$ (XRD-7000, Shimadzu, Japan). UV-vis spectrum of the AgNPs suspension was collected with a UV-2550 spectrophotometer (Shimadzu, Japan). All electrochemical measurements were carried out with the modified GCE as a working electrode, a Pt counter electrode and a $\mathrm{Ag} / \mathrm{AgCl}$ reference electrode. The electrochemical data were obtained using a CHI 660E electrochemical workstation (Shanghai Chenhua Apparatus Corporation, China).

\section{Results and discussion}

Since shape and size of AgNPs are critical parameters for the antimicrobial activity, transmission electron microscopy (TEM) was carried out to characterize the morphology of the asprepared nanosilver. Nanoparticles with uniform shape and size can be observed in Fig. 1A. The TEM image with a higher magnification (Fig. 1B) clearly shows the spherical shape of a single nanoparticle. By measuring diameter of the nanoparticles in the TEM images, the size distribution of the AgNPs is exhibited in Fig. 1C. The AgNPs vary from 1.0 to $9.0 \mathrm{~nm}$ and possess an average value of $4.5 \mathrm{~nm}$. Both shape and size of the as-prepared AgNPs are consistent with those reported in previous literatures. ${ }^{36}$ A well-defined peak located at $394 \mathrm{~nm}$ can be found in the UV-vis spectrum of the AgNPs suspension (Fig. 1D), attributing to the surface plasmon resonance 

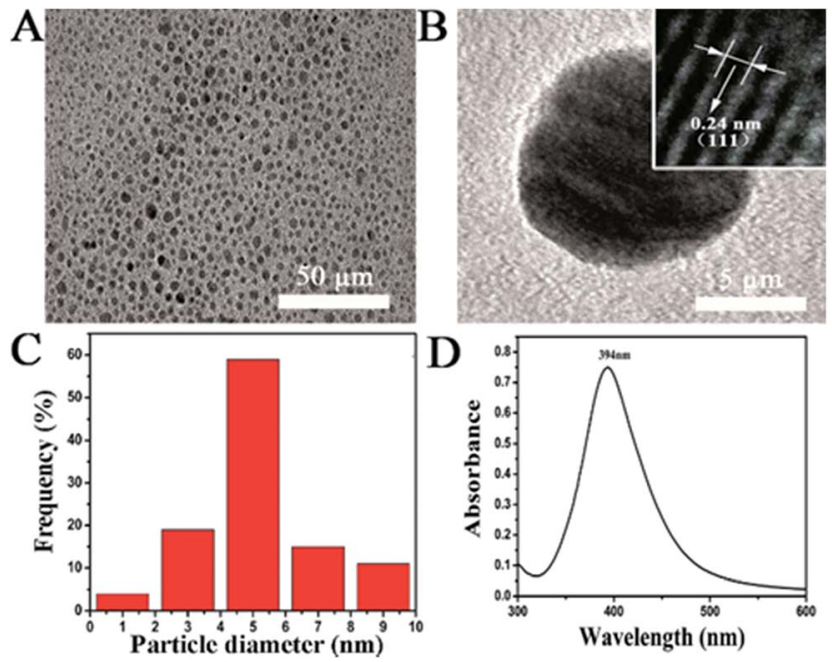

Fig. 1 Characterization of the as-prepared AgNPs. (A) TEM image of the AgNPs; (B) TEM image of a single AgNP; (C) particle size distribution of the AgNPs; (D) UV-vis spectrum of a AgNPs suspension.

absorption peak of AgNPs. The above results verify the successful synthesis of AgNPs with the spherical shape and an average size of $\sim 4.5 \mathrm{~nm}$, the quality of which can meet the requirements of the following biological tests. Before its application in anti-fungal assays, the freshly prepared AgNPs have been stored at $4{ }^{\circ} \mathrm{C}$ for 4 days. In comparison to the data in Fig. 1D, there is no significant change on the UV-vis spectrum of the stored AgNPs suspension (Fig. S1 $\uparrow$ ), suggesting the good stability of AgNPs during the storage process. The stability of AgNPs in the culture medium was also investigated with the dynamic laser scattering technique (Fig. S2 $\dagger$ ). After an incubation in a culture medium for 4 days, the hydrodynamic size of AgNPs increases to $\sim 7.5 \mathrm{~nm}$. The results indicate that the AgNPs are quite stable in the culture medium and the surface adsorption of small peptides may cause the increment of the nanoparticle size.

To investigate effects of the AgNPs exposure on fungal growth, dry weight of A. flavus mycelium balls before/after AgNPs treatments were measured. As the dose of AgNPs in the system increases, weight of the mycelium balls gradually decreases (Fig. 2A). When the AgNPs dose reaches to $60 \mu \mathrm{g}$ $\mathrm{mL}^{-1}$, the weight is very close to zero (Table $\mathrm{S} 1 \dagger$ ), suggesting the complete inhibition of A. flavus growth by AgNPs. The results indicate that the AgNPs could effectively inhibit the A. flavus growth in a dose-dependent manner, agreeing well with the anti-fungal activity of AgNPs. Undoubtedly, the AgNPs-caused growth inhibition could significantly reduce the fungal amount in the system, further resulting in the decrease of aflatoxin production. At high doses (more than $15 \mu \mathrm{g} \mathrm{mL}{ }^{-1}$ ), AgNPs-induced direct reduction of aflatoxins cannot be differentiated from the indirect one that was caused by the fungal amount decrease. As shown in Fig. 2A, AgNPs have no significant effect on the A. flavus growth at $5 \mu \mathrm{g} \mathrm{mL} \mathrm{m}^{-1}$. The growth of $A$. flavus exposed to $5 \mu \mathrm{g} \mathrm{mL}{ }^{-1}$ AgNPs in a liquid culture medium was shown in Fig. S3 in ESI. $\dagger$ Moreover, morphologies of the mycelia treated with $5 \mu \mathrm{g} \mathrm{mL}{ }^{-1}$ AgNPs are similar to those in
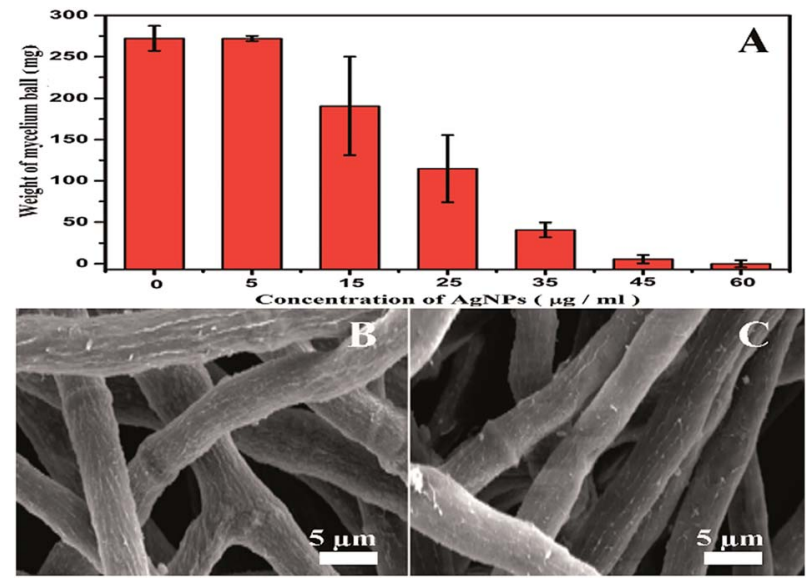

Fig. 2 Effects of AgNPs exposure on the growth of $A$. flavus. (A) Dosedependent reduction of the dry weight of mycelium balls; (B) surface morphologies of the mycelia after the PBS treatment; (C) surface morphologies of the mycelia after the AgNPs treatment $\left(5 \mu \mathrm{g} \mathrm{mL}^{-1}\right)$.

control group (Fig. 2B and C). Therefore, the concentration of 5 $\mu \mathrm{g} \mathrm{mL}{ }^{-1}$ is selected in the following assays to explore the direct inhibition effects of AgNPs on the aflatoxin production from $A$. flavus. It has been reported that the antimicrobial activity of nanosilver may be caused by the penetration of the nanoparticles into the microbes. ${ }^{14}$ Since the size of AgNPs is less than $5 \mathrm{~nm}$, their binding and penetration cannot be directly observed in the SEM images. TEM was also conducted to check the morphology of the filamentous fungi (Fig. S4†). However, the attachment and penetration of AgNPs were not observed in our investigation.

After exposure to $5 \mu \mathrm{g} \mathrm{mL} \mathrm{m}^{-1}$ AgNPs, the mycelia were harvested by centrifugation, further culturing in a fresh medium for $96 \mathrm{~h}$. The media were collected at 0,72 and $96 \mathrm{~h}$ for aflatoxin measurements (Table 1). At the beginning of incubation, amounts of $\mathrm{AFB}_{1}$ in the culture media are quite low (around 3-4 $\mathrm{ng} \mathrm{mL}^{-1}$ ) in both PBS- and AgNPs-treated samples. Desorption of aflatoxin molecules from the mycelium may lead to the initial amount of $\mathrm{AFB}_{1}$. After incubation for $72 \mathrm{~h}$, there is a significant enhancement on the $\mathrm{AFB}_{1}$ concentration. As the incubation time elongates to $96 \mathrm{~h}$, the amount of $\mathrm{AFB}_{1}$ further increases. $\mathrm{AFB}_{1}$ has been bio-synthesized and gradually secreted into the culture media by A. flavus during the culture process in both control and AgNPs-exposed groups. By comparing both groups, it can be found that the pre-treatment of AgNPs could induce an obvious reduction on the $\mathrm{AFB}_{1}$ concentrations in the culture media. After a $96 \mathrm{~h}$ culture, the average $\mathrm{AFB}_{1}$ concentration in the AgNPs-exposed sample is around $28.96 \mathrm{ng} \mathrm{mL}^{-1}$, which is lesser than that in the PBS-treated one. The results strongly support that an instantaneous stimulation of A. flavus by AgNPs could effectively depress the generation of $\mathrm{AFB}_{1}$.

Electrochemical biosensor is a well-established method for in situ monitoring important biomolecules in biological systems. ${ }^{29,31,32,37} \mathrm{O}_{2}{ }^{-}$is one of the ROS with high activity and short half-life. The measurement of $\mathrm{O}_{2}{ }^{-}$in a biological system is quite difficult. In the present work, $\mathrm{O}_{2}{ }^{-}$was chosen as a typical type of ROS to investigate the role of ROS in AgNPs-caused 
Table 1 Production of $\mathrm{AFB}_{1}$ from the PBS and AgNPs-treated A. flavus

\begin{tabular}{|c|c|c|c|c|}
\hline Time (h) & \multicolumn{2}{|l|}{ PBS } & \multicolumn{2}{|l|}{ AgNPs } \\
\hline 72 & $24.44 \pm 2.15$ & $21.22 \pm 3.35$ & $17.17 \pm 0.98$ & $13.15 \pm 3.14$ \\
\hline 96 & $66.23 \pm 6.60$ & $63.01 \pm 7.80$ & $28.96 \pm 1.14$ & $24.94 \pm 3.30$ \\
\hline
\end{tabular}

suppression of $\mathrm{AFB}_{1}$ production. In order to real-time study the possible role of $\mathrm{O}_{2}{ }^{-}$in the AgNPs-induced inhibition of $\mathrm{AFB}_{1}$ production, we synthesized $\mathrm{Mn}_{3} \mathrm{O}_{4}$ nanorod, a specific artificial nano-enzyme of $\mathrm{O}_{2}{ }^{-}$, for the fabrication of an $\mathrm{O}_{2}$ - electrochemical biosensor. The as-prepared products are rodshaped materials with the diameter of $\sim 100 \mathrm{~nm}$ and the length of $\sim 200 \mathrm{~nm}$ (Fig. 3A and B). The XRD pattern (Fig. 3C) displays several diffraction peaks, matching well with (101), (112), (200), (103), (211), (004), (220), (105), (312), (303), (224), (215) and (400) planes of tetragonal $\mathrm{Mn}_{3} \mathrm{O}_{4}$ (JCPDS card 240734). The scanning electron microscope (SEM) images and the X-ray diffraction (XRD) data verify the successful synthesis of $\mathrm{Mn}_{3} \mathrm{O}_{4}$ nanorods. After layer-by-layer deposition of MWCNTs and $\mathrm{Mn}_{3} \mathrm{O}_{4}$ nanorods, surface morphology of the modified electrode was imaged with SEM (Fig. 3D). A layer of nanorods covers on a network structure, clearly proving the existence of MWCNTs and $\mathrm{Mn}_{3} \mathrm{O}_{4}$ nanorods on the surface of the electrode.

During the catalytic process, a $\mathrm{O}_{2}{ }^{-}$oxidizes the $\mathrm{Mn}^{2+}$ to produce $\mathrm{MnO}_{2}{ }^{+}$and $\mathrm{H}_{2} \mathrm{O}_{2}$ while another $\mathrm{O}_{2}{ }^{-}$simultaneously reduces the $\mathrm{MnO}_{2}^{+}$to produce $\mathrm{Mn}^{2+}$ and $\mathrm{O}_{2}$. Performances of the electrochemical sensor including the sensitivity, dynamic range and specificity were investigated before its application in the system containing fungi. The amperometric responses of the sensor to successive addition of $\mathrm{O}_{2}{ }^{-}$is recorded at an applied potential of $700 \mathrm{mV}$ (Fig. 4A). The response time is less
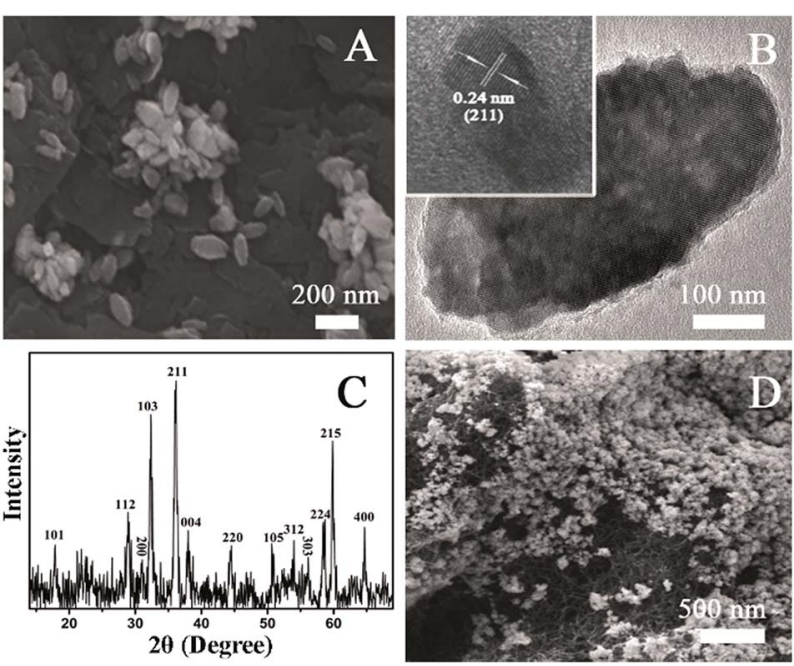

Fig. 3 Characterization of the as-prepared $\mathrm{Mn}_{3} \mathrm{O}_{4}$ nanorods and the electrode surface. (A) SEM image of the $\mathrm{Mn}_{3} \mathrm{O}_{4}$ nanorods; (B) TEM image of a single $\mathrm{Mn}_{3} \mathrm{O}_{4}$ nanorod; (C) XRD pattern of the $\mathrm{Mn}_{3} \mathrm{O}_{4}$ nanorods; (D) SEM image of the surface of the $\mathrm{Mn}_{3} \mathrm{O}_{4}$ nanorodsMWCNTs-modified electrode. than $5 \mathrm{~s}$ in response to a step injection of $\mathrm{O}_{2}{ }^{-}$. Well-defined steady-state currents can be obtained in a range of 57.5 to $862.5 \mathrm{nM}$, in which there is a linear relationship with a correlation coefficient of 0.999 between the current intensity and the $\mathrm{O}_{2}{ }^{-}$concentration (Fig. 4B). The detection limit of $19.87 \mathrm{nM}$ (S/ $\mathrm{N}=3$ ) and the sensitivity of $6.26 \mu \mathrm{A} \mu \mathrm{M}^{-1}$ can be calculated based on the calibration curve (Fig. 4B). ${ }^{38}$ The specificity of the $\mathrm{O}_{2}{ }^{-}$sensor is shown in Fig. $4 \mathrm{C}$ and D. The additions of $1 \mu \mathrm{M}$ common compounds and ions existed in biological systems including $\mathrm{H}_{2} \mathrm{O}_{2}$, ascorbic acid (AA), $\mathrm{Na}^{+}, \mathrm{NO}_{3}{ }^{-}, \mathrm{Cl}^{-}$and dopamine (DA) do not lead to significant current responses. While, $57.5 \mathrm{nM} \mathrm{O}_{2}{ }^{-}$can trigger a dramatic increment of the current signal. The findings reveal that the MWCNTs- $\mathrm{Mn}_{3} \mathrm{O}_{4}$ nanorodsmodified electrode with a low detection limit, a high sensitivity and excellent specificity for $\mathrm{O}_{2}{ }^{-}$detection could be utilized in real-time detection of $\mathrm{O}_{2}{ }^{-}$released from A. flavus.

The secretion of $\mathrm{O}_{2}{ }^{-}$from A. flavus with/without AgNPs treatment was real-time monitored using the electrochemical sensor. As shown in Fig. 5, the addition of PBS in the A. flavus system does not cause any electrochemical response (red line). The data rule out the interference of the solvent in the electrochemical detection. Upon the injection of a $5 \mu \mathrm{g} \mathrm{mL}{ }^{-1}$ AgNPs suspension, an obvious increase of the current occurs (black line). To validate that the current change is indeed caused by $\mathrm{O}_{2}{ }^{-}$, superoxide dismutase (SOD), a selective scavenger of $\mathrm{O}_{2}{ }^{-}$,
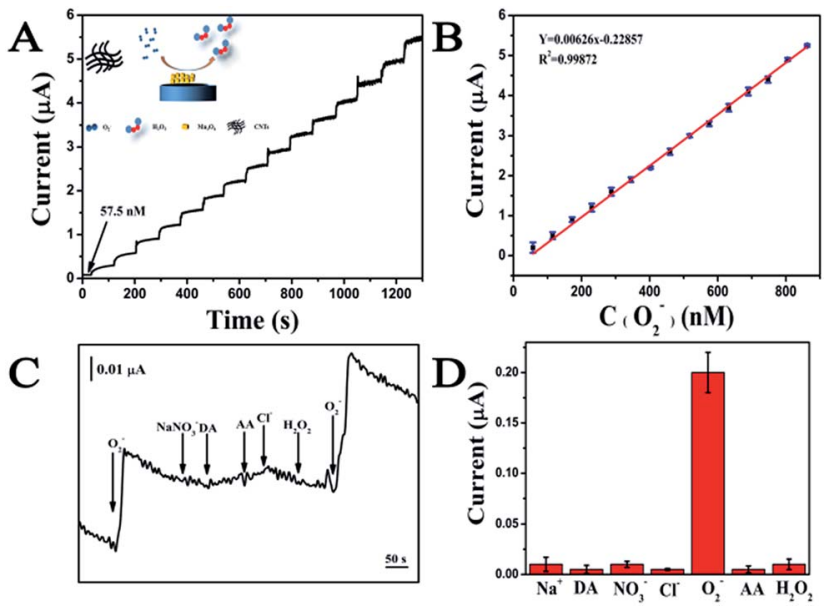

Fig. 4 Performance of the $\mathrm{O}_{2}{ }^{-}$electrochemical sensor. (A) Amperometric responses of the sensor on successive injection of $\mathrm{O}_{2}{ }^{-}$into a PBS buffer (0.01 M, pH 6); (B) plots of the response current versus the $\mathrm{O}_{2}{ }^{-}$concentration; (C) amperometric responses of the sensor to ascorbic acid (AA), $\mathrm{Na}^{+}, \mathrm{NO}_{3}^{-}, \mathrm{Cl}^{-}$, dopamine (DA) and $\mathrm{H}_{2} \mathrm{O}_{2}$; (D) responses of the sensor to $10 \mu \mathrm{M}$ interferes and $57.5 \mathrm{nM} \mathrm{O}_{2}{ }^{-}$. 


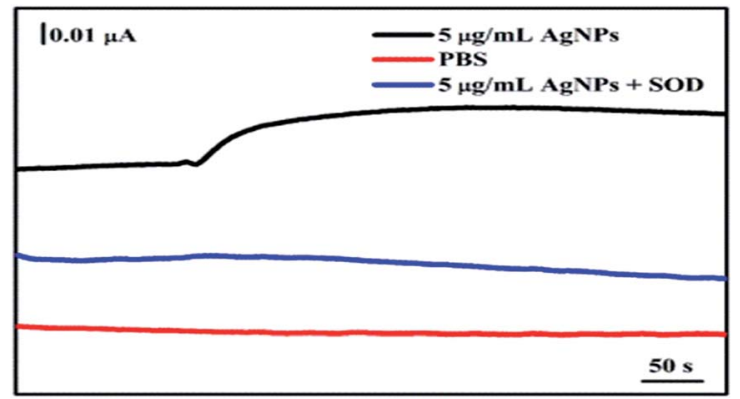

Fig. 5 Real-time monitoring the AgNPs-induced $\mathrm{O}_{2}{ }^{-}$release from $A$. flavus. Amperometric responses of the sensor in a PBS solution without $A$. flavus (red line), a PBS solution containing $A$. flavus upon the injection of $5 \mu \mathrm{g} \mathrm{mL}^{-1}$ AgNPs suspension (black line), as well as a PBS solution containing $A$. flavus upon the injection of $5 \mu \mathrm{g} \mathrm{mL}^{-1}$ AgNPs suspension and equal volume of SOD $\left(50 \mathrm{U} \mathrm{mL}^{-1}\right)$ (blue line).

was introduced in the detection system. SOD-catalyzed dismutation of $\mathrm{O}_{2}{ }^{-}$may generate hydrogen peroxide, which does not interfere the electrochemical monitoring of $\mathrm{O}_{2}{ }^{-}$as being illustrated in Fig. 4C and D. The existence of SOD could eliminate the current enhancement induced by AgNPs (blue line). The data indicate that the treatment of AgNPs could stimulate the fungal mycelia to release $\mathrm{O}_{2}{ }^{-}$rapidly. According to the calibration curve in Fig. 4B, the amount of the $\mathrm{O}_{2}{ }^{-}$released from AgNPs-exposed A. flavus is around $41.3 \mathrm{nM}$ (the weight concentration of mycelia in the testing system is $\left.1.15 \mathrm{~g} \mathrm{~mL}^{-1}\right)$. In order to directly analyze the function of $\mathrm{O}_{2}{ }^{-}$in nanosilverinduced aflatoxin suppression, experiments need to be carried out to investigate influences of AgNPs on the expression of ROSrelated genes in future works.

In the present study, $\mathrm{AFB}_{1}$ released into the culture medium was measured to represent the amount of aflatoxins synthesized by the A. flavus cells. Since ROS are closely related to the biosynthesis of aflatoxins, a possible mechanism involving quick release of $\mathrm{O}_{2}{ }^{-}$is proposed to explain the AgNPs-caused inhibition of $\mathrm{AFB}_{1}$ production from A. flavus on the basis of the above data (Fig. 6). The moderate accumulation of ROS in $A$. flavus mycelia could initiate a series of biochemical reactions for the aflatoxin biosynthesis. Upon the stimulation of AgNPs, $\mathrm{O}_{2}{ }^{-}$molecules are secreted from the mycelia immediately,

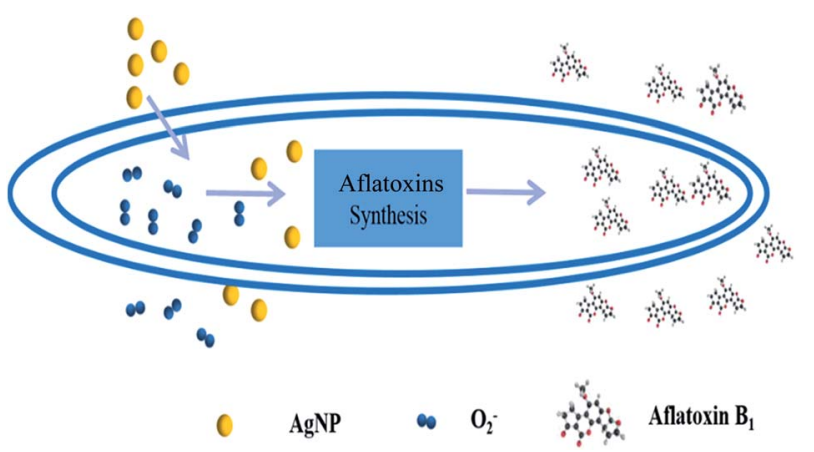

Fig. 6 Mechanism for AgNPs-caused suppression of aflatoxin production in A. flavus. ultimately resulting in the quick reduction of intracellular ROS level. The low intracellular oxidative level further influences the signalling pathway to the aflatoxin biosynthesis. Finally, the production of aflatoxins in A. flavus is significantly suppressed. In future works, effects of AgNPs on the secretion of other ROS such as hydroxyl radical and $\mathrm{H}_{2} \mathrm{O}_{2}$ in A. flavus should be investigated to further reveal the role of ROS in the mycotoxin production. It should also be noted that the inhibiting effects of AgNPs on the release process might also affect the reduction of aflatoxin secretion. As far as we known, there is no report on AgNPs-induced secreting inhibition of aflatoxin-containing vesicles. Thus, the mechanism for antifungal activity and aflatoxin reduction caused by AgNPs needs to be further investigated.

\section{Conclusions}

In summary, AgNPs-induced suppression of $\mathrm{AFB}_{1}$ production from A. flavus and its possible mechanism have been investigated in the present work. AgNPs synthesized with a wetchemical approach were characterized using TEM and UV-vis spectrometry. Based on the anti-fungal assay, $5 \mu \mathrm{g} \mathrm{mL} \mathrm{L}^{-1}$ was selected as the concentration in the aflatoxin production and $\mathrm{O}_{2}{ }^{-}$release tests to avoid the interferences of indirect aflatoxin reduction due to the fungal growth inhibition. The exposure of A. flavus to AgNPs could significantly decrease the secretion of $\mathrm{AFB}_{1}$. The real-time measurements of $\mathrm{O}_{2}{ }^{-}$with a MWCNTs$\mathrm{Mn}_{3} \mathrm{O}_{4}$ nanorods-based electrochemical sensor show that the AgNPs could trigger the release of $\mathrm{O}_{2}{ }^{-}$from fungal mycelia rapidly. A mechanism involving $\mathrm{O}_{2}{ }^{-}$release is proposed to explain the AgNPs-caused depression of aflatoxin production from A. flavus. This is the first attempt to study AgNPs-induced inhibition on aflatoxin generation. The electrochemical sensors fabricated in the present study could also be used to investigate other $\mathrm{O}_{2}{ }^{-}$related biological systems in future works.

\section{Acknowledgements}

This work is financially supported by National Program on Key Basic Research Project of China (973 Program) under contract No. 2013CB127804, Natural Science Foundation of Hubei (2015CFB578), Funding for Health Bureau of Wuhan (2014WX14A04) and Fundamental Research Funds for the Central Universities under XDJK2015B016. Z. S. Lu would like to thank the supports by the Specialized Research Fund for the Doctoral Program of Higher Education (RFDP) (Grant No. 20130182120025) and Young Core Teacher Program of the Municipal Higher Educational Institution of Chongqing.

\section{Notes and references}

1 M. Thompson and R. Wood, Pure Appl. Chem., 1995, 67, 649666.

2 M. Thompson and S. L. R. Ellison, Accredit. Qual. Assur., 2006, 11, 373-378.

3 M. Thompson, S. L. R. Ellison and R. Wood, Pure Appl. Chem., 2006, 78, 145-196. 
4 D. L. Duewer, Accredit. Qual. Assur., 2008, 13, 193-216.

5 J. S. Wang and J. D. Groopman, Mutat. Res., Fundam. Mol. Mech. Mutagen., 1999, 424, 167-181.

6 R. Bluma, M. R. Amaiden and M. Etcheverry, Int. J. Food Microbiol., 2008, 122, 114-125.

7 J. S. Dambolena, A. G. López, M. C. Cánepa, M. G. Theumer, J. A. Zygadlo and H. R. Rubinstein, Toxicon, 2008, 51, 37-44.

8 H. Hua, F. Xing, J. N. Selvaraj, Y. Wang, Y. Zhao, L. Zhou, X. Liu and Y. Liu, PLoS One, 2013, 9, e108285.

9 B. Jeršek, U. N. Poklar, M. Skrt, N. Gavarić, B. Božin and M. S. Smole, Arh. Hig. Rada Toksikol., 2014, 65, 199-208.

10 E. Kim and I. K. Park, Molecules, 2012, 17, 10459-10469.

11 M. C. Manganyi, T. Regnier and E. I. Olivier, S. Afr. J. Bot., 2015, 99, 115-121.

12 S. Kang, M. Pinault and L. D. Pfefferle, Langmuir, 2007, 23, 8670-8673.

13 S. Liu, L. Wei and L. Hao, ACS Nano, 2016, 3, 3891-3902.

14 S. Kang, M. S. Mauter and M. Elimelech, Environ. Sci. Technol., 2008, 42, 7528.

15 X. Wang, X. Liu and H. Han, Colloids Surf., B, 2013, 103, 136142.

16 X. Wang, X. Liu and J. Chen, Carbon, 2014, 68, 798-806.

17 X. Cui, C. M. Li, H. Bao, X. Zheng and Z. Lu, J. Colloid Interface Sci., 2008, 327, 459-465.

18 L. Guo, W. Yuan, Z. Lu and C. M. Li, Colloids Surf., A, 2013, 439, 69-83.

19 Z. Lu, M. Meng, Y. Jiang and J. Xie, Colloids Surf., A, 2014, 447, 1-7.

20 M. Rai, A. Yadav and A. Gade, Biotechnol. Adv., 2009, 27, 7683.

21 J. Robidoux, T. L. Martin and S. Collins, Toxicol. Appl. Pharmacol., 2004, 44, 297-323.

22 C. A. Campos, L. N. Gerschenson and S. K. Flores, Food Bioprocess Technol., 2011, 4, 849-875.
23 H. E. Qiang and L. V. Yuan-Ping, Trends Food Sci. Technol., 2008, 281-298.

24 B. B. N. Ames, M. K. Shigenaga and T. M. Hagen, Biochim. Biophys. Acta, 1995, 1271, 165-170.

25 M. Akbarian, M. E. Olya, M. Ataeefard and M. Mahdavian, Prog. Org. Coat., 2012, 75, 344-348.

26 R. A. Floyd, FASEB J., 1990, 4, 2587-2597.

27 E. D. Hall and J. M. Braughler, Free Radical Biol. Med., 1989, 6, 303-313.

28 A. Vanella, G. C. Di, V. Sorrenti, A. Russo, C. Castorina, A. Campisi, M. Renis and J. R. Perez-Polo, Neurochem. Res., 1993, 18, 1337-1340.

29 X. T. Zheng, W. Hu, H. Wang, H. Yang, W. Zhou and C. M. Li, Biosens. Bioelectron., 2011, 26, 4484-4490.

30 J. Li, J. Li, Z. Lu, Y. Liu and C. M. Li, Chem. Commun., 2015, 51, 17424.

31 M. Reverberi, S. Zjalic, A. Ricelli, A. A. Fabbri and C. Fanelli, Mycotoxin Res., 2006, 22, 39-47.

32 T. Jayashree and C. Subramanyam, Free Radical Biol. Med., 2000, 29, 981-985.

33 J. H. Kim, B. C. Campbell, R. Molyneux, N. Mahoney, K. L. Chan, J. Yu, J. Wilkinson, J. Cary, D. Bhatnagar and T. E. Cleveland, Mycotoxin Res., 2006, 22, 3-8.

34 R. Rachmawati, H. Kinoshita and T. Nihira, Procedia Environ. Sci., 2013, 17, 142-149.

35 T. Jayashree, J. P. Rao and C. Subramanyam, FEMS Microbiol. Lett., 2000, 183, 215-219.

36 N. Shirtcliffe, U. Nickel and S. Schneider, J. Colloid Interface Sci., 1999, 211, 122-129.

37 Y. Luo, Y. Tian and Q. Rui, Chem. Commun., 2009, 21, 30143016.

38 L. Yu, L. X. Gao, X. Q. Ma, F. X. Hu, C. M. Li and Z. Lu, Integr. Biol., 2014, 6, 1211-1217. 